This is the peer-reviewed version of the following article: Thijssen, S., Muetzel, R.L., Bakermans-Kranenburg, M.J., Jaddoe, V.W.V., Tiemeier, H., Verhulst, F.C., White, T., \& van IJzendoorn (2017), Insensitive parenting may accelerate the development of the amygdalamedial prefrontal cortex circuit which has been published in final form in Development and Psychopathology, 29, 2, 505-518. DOI:10.1017/S0954579417000141. This article may be used for non-commercial purposes in accordance with Cambridge University Press Policy for Green Open Access

\title{
Insensitive Parenting May Accelerate the Development of the Amygdala-Medial Prefrontal Cortex Circuit
}

\footnotetext{
Thijssen, S. ${ }^{\text {a,b }}$, Muetzel, R. L. ${ }^{\text {b,c }}$, Bakermans-Kranenburg, M.J. ${ }^{\text {a,d }}$, Jaddoe., V. W. V. ${ }^{\text {be,f }}$, Tiemeier, H. ${ }^{\text {b,c,e,g }}$, Verhulst, F. C. ${ }^{\text {b,c }}$, White, T. ${ }^{\text {c,h }} \&$ Van IJzendoorn, M. H. ${ }^{\text {a,d,i }}$

${ }^{a}$ Centre for Child and Family Studies, Leiden University, Leiden; the Netherlands; ${ }^{\mathrm{b}}$ The Generation R Study Group, Erasmus University Medical Center, Rotterdam, the Netherlands; ${ }^{c}$ Department of Child and Adolescent Psychiatry/Psychology, Erasmus University Medical Center-Sophia Children's Hospital, Rotterdam, the Netherlands; ${ }^{\mathrm{d}}$ Leiden Institute for Brain and Cognition (LIBC), Leiden University, Leiden, the Netherlands; ${ }^{\text {e }}$ Department of Epidemiology, Erasmus University Medical Center, Rotterdam, the Netherlands; ${ }^{\mathrm{f}}$ Department of Pediatrics, Erasmus University Medical Center, Rotterdam, the Netherlands; ${ }^{\mathrm{g}}$ Department of Psychiatry, Erasmus University Medical Center; ${ }^{\mathrm{h}}$ Department of Radiology, Erasmus University Medical Center, Rotterdam, the Netherlands; ${ }^{i}$ the School of Pedagogical and Educational Sciences, Erasmus University Rotterdam, Rotterdam, the Netherlands;
} 
Acknowledgements

The Generation R Study is conducted by the Erasmus Medical Center in close collaboration with the Erasmus University Rotterdam, School of Law and Faculty of Social Sciences, the Municipal Health Service Rotterdam area, Rotterdam, the Rotterdam Homecare Foundation, Rotterdam, and the Stichting Trombosedienst \& Artsenlaboratorium Rijnmond (STAR), Rotterdam. The first phase of the Generation R Study is made possible by financial support from: Erasmus Medical Centre, Rotterdam, Erasmus University Rotterdam and the Netherlands Organization for Health Research and Development (ZonMw), the Netherlands Organisation for Scientific Research (NWO), the Ministry of Health, Welfare and Sport and the Ministry of Youth and Families. In addition, this study is financially supported through ZonMw TOP project number 91211021 (TW). HT, MJB-K and MHvIJ were supported by research awards from the Netherlands Organization for Scientific Research (HT: VIDI grant; MHvIJ: SPINOZA prize; MJBK: VICI grant), and by the Gravitation program of the Dutch Ministry of Education, Culture, and Science and the Netherlands Organization for Scientific Research (NWO grant number 024.001.003). MJBK was also supported by the European Research Council (ERC AdG).

Corresponding author:

Prof. dr. Henning Tiemeier The Generation R Study Group Erasmus Medical Center, P.O. Box 2040

3000 CA Rotterdam, the Netherlands

E-mail: h.tiemeier@erasmusmc.nl

Phone: 0031-10-7043447 


\begin{abstract}
This study examined whether the association between age and amygdala-mPFC connectivity in typically developing 6-10-year old children is correlated with parental care. Resting-state functional magnetic resonance imaging scans were acquired from 124 children of the Generation R Study who at 4 years had been observed interacting with their parents to assess maternal and paternal sensitivity. Amygdala functional connectivity was assessed using a general linear model with the amygdalae time-series as explanatory variables. Higher-level analyses assessing sensitivity $\times$ age as well as exploratory sensitivity $\times$ age $\times$ gender interaction effects were performed restricted to voxels in the $\mathrm{mPFC}$. We found significant sensitivity $\times$ age interaction effects on amygdala-mPFC connectivity. Age was related to stronger amygdala-mPFC connectivity in children with a lower combined parental sensitivity score $(b=0.11, p=.004$, $b=0.06, p=.06$, right and left amygdala, respectively), but not in children with a higher parental sensitivity score, $(b=-0.7, p=.12, b=-0.06, p=.12$ right and left amygdala, respectively). A similar effect was found for maternal sensitivity, with stronger amygdala-mPFC connectivity in children with less sensitive mothers. Exploratory (parental, maternal, paternal) sensitivity $\times$ age $\times$ gender interaction analyses suggested that this effect was especially pronounced in girls. AmygdalamPFC resting-state functional connectivity has been shown to increase from age 10.5 years onwards, implying that the positive association between age and amygdala-mPFC connectivity in 6-10-year old children of less sensitive parents represents accelerated development of the amygdala-mPFC circuit.
\end{abstract}


The amygdala and medial prefrontal cortex (mPFC) are brain regions important for emotion regulation. The amygdala is involved in emotional learning and may facilitate attention to salient cues (Phelps \& LeDoux, 2005), whereas the mPFC has been implicated in higher-order emotional functioning (Forbes \& Grafman, 2010; Miller, 2002). As the mPFC is suggested to provide top-down regulation of amygdala reactivity, functional coupling of the amygdala and mPFC may be particularly important for regulating emotions (Hariri, Mattay, Tessitore, Fera, \& Weinberger, 2003; Ochsner, Bunge, Gross, \& Gabrieli, 2002; Phan et al., 2005). In children, the amygdala-mPFC circuit is still developing. While the amygdala-mPFC circuit is immature, parents may play an important role in child emotion regulation (Tottenham, 2015). As a consequence, adverse caregiving may affect amygdala and mPFC development. Indeed, several studies have suggested that extreme caregiving experiences, such as institutionalized care, are associated with amygdala and mPFC structure and function (Banihashemi, Sheu, Midei, \& Gianaros, 2015; Dannlowski et al., 2013; Tottenham et al., 2010; Whittle et al., 2009), as well as amygdala-mPFC circuit development (Gee, Gabard-Durnam, et al., 2013). However, results obtained in high-risk samples may not be generalizable to the general population. Here, we examined whether the development of the amygdala-mPFC circuit is modulated by typical variation in parental care.

Evidence suggests that the amygdala develops earlier than the mPFC, which may not show mature structure until late adolescence or early adulthood (Giedd et al., 1996; Shaw et al., 2008). This would imply that during childhood, the immature mPFC may not be capable of fully regulating amygdala (re)activity. Indeed, amygdala reactivity to fearful stimuli decreases with age (Gee, Humphreys, et al., 2013; Guyer et al., 2008). Moreover, Gee et al. (2013) showed that this decrease in amygdala activity with age is accompanied by a switch from positive to negative 
coupling of the amygdala-mPFC circuit at approximately 10 years of age. Further evidence for the continuing development of the amygdala-mPFC circuit during childhood and adolescence comes from studies showing that task-based connectivity of the amygdala-mPFC circuit increases with age (Decety, Michalska, \& Kinzler, 2012; Perlman \& Pelphrey, 2011). For children younger than 10.5 years, no evidence was found for functional coupling between the amygdala and $\mathrm{mPFC}$ in the brain at rest, whereas for children from 10.5 years onwards there was a positive association between amygdala-mPFC connectivity and age (Gabard-Durnam et al., 2014).

In the absence of a mature amygdala-mPFC circuit, the child's emotionality may be externally regulated by parental presence (Tottenham, 2015). For example, children show greater approach-related behavior, greater exploration, and lower levels of stress hormones in the presence of their parent than in presence of a stranger or left alone (Ainsworth \& Bell, 1970; Hostinar, Johnson, \& Gunnar, 2015). In rodent pups, maternal presence reduced amygdala activity during odor-shock conditioning (Moriceau \& Sullivan, 2006), while in human participants, parental presence normalized anxious youth' mPFC activation in response to stressful stimuli (Conner et al., 2012).

Early caregiving adversity affects brain development. In rats, maternal deprivation has been associated with accelerated development of fear-based learning (Callaghan \& Richardson, 2011), which has been ascribed to the amygdala-mPFC circuit (Akirav \& Maroun, 2007). Moreover, institutionalized care has been associated with structural abnormalities in the amygdala (Mehta et al., 2009; Tottenham et al., 2010). Adults who report a history of early maltreatment exhibit exaggerated amygdala reactivity in response to emotional stimuli (Dannlowski et al., 2013), and previously institutionalized children have been shown to exhibit 
reduced amygdala discrimination between mothers versus strangers, which is associated with indiscriminate friendliness (Olsavsky et al., 2013). Comparable to fear-based learning, maturation of the amygdala-mPFC circuit may be accelerated in the absence of supportive parental care. Although family-reared children do not show negative coupling between the amygdala and the mPFC until the age of 10 years (while watching fearful faces, Gee, Humphreys, et al., 2013), previously institutionalized youth have been shown to demonstrate negative coupling earlier in development (Gee, Gabard-Durnam, et al., 2013).

The finding of accelerated maturation in response to caregiving adversity is in line with the Belsky, Steinberg, and Draper (1991) evolutionary theory of reproductive development. They theorized that children adaptively adjust their development to match local conditions. Parental care and investment provide children with information about availability and predictability of resources and relationships. Low levels of parental care or investment suggest scarcity of resources and low quality of interpersonal relationships. According to this theory, children respond to low levels of parental care by speeding up development, as this may ultimately increase their reproductive success. Building on this theory, Callaghan and Tottenham (2016b) suggest that early life stress may prematurely activate the development of neural structures important for emotion regulation. Although a long childhood is critical for the development and practice of highly competent behavior and long-term well-being, it may be adaptive in the short run to self-regulate instead of rely on a parent for emotion regulation when quality of parental care is low, even at the cost of long-term health or well-being (Belsky, Ruttle, Boyce, Armstrong, \& Essex, 2015; Hochberg \& Belsky, 2013).

Due to the relatively extreme caregiving experiences, results obtained in high-risk samples such as previously institutionalized children may not be generalizable to the general 
population. More importantly, the influence of unmeasured confounders and third variables (such as nutritional deficiencies, congenital diseases, and lack of cognitive stimulation) in the mostly somewhat 'messy' designs that are inevitably characteristic of deprivation-related studies of child development in high-risk samples, makes converging evidence from relatively normal, typical variations in parenting and the effects on brain development even more crucial.

Ultimately, developmental pathways can only be understood when both typical and atypical processes are considered (Cicchetti, 2016; Sroufe, 1990). Although there is compelling evidence that normal variation in early caregiving has a long-term impact on child behavior, emotional regulation and executive functioning (Bernier, Carlson, Deschenes, \& Matte-Gagne, 2012; Kok, Linting, et al., 2013; Lucassen et al., 2015; Newton, Laible, Carlo, Steele, \& McGinley, 2014; Rijlaarsdam et al., 2013), research on normal variation in parental care and brain development is scarce. Sensitive parental care is characterized by prompt and adequate responses to the child's signals and needs (Ainsworth, Bell, \& Stayton, 1974). Maternal sensitivity has been shown to predict reduced growth in the amygdala and greater thinning of the orbitofrontal cortex four years later (Whittle et al., 2014). Moreover, insecure attachment during infancy may predict larger amygdala volume in adulthood (Moutsiana et al., 2015), and lower levels of early parental sensitivity in a typically developing, non-clinical sample was associated with smaller total brain volume and grey matter volume (controlled for infant head size) later in childhood (Kok et al., 2015). However, this study did not find an association between early parental insensitivity and amygdala volume at 8 years.

The present cross-sectional magnetic resonance imaging (MRI) study examined whether the association between age and amygdala-mPFC connectivity in 6-to 10-year old children is correlated with normal variation in parental care. Gabard-Durnam et al. (2014) found that 
resting-state functional coupling between the amygdala and $\mathrm{mPFC}$ increases from age 10.5 years onwards. We hypothesized that children from less sensitive parents show accelerated development of the amygdala-mPFC circuit, with amygdala-mPFC coupling already increasing over age in the period from 6-to 10-years. In children from more sensitive parents, amygdalamPFC coupling would not yet show an increase with age in the current sample. Moreover, as several studies provide evidence that parents may have differential effects on the neurobiology of male and female offspring (Ellis, Schlomer, Tilley, \& Butler, 2012; Wu et al., 2014; Yu et al., 2012), we explored sensitivity $\times$ age $\times$ sex interaction effects.

\section{Methods}

\section{Participants}

The study was embedded within the Generation R Study, a prospective cohort investigating growth, development, and health from fetal life onwards in Rotterdam, the Netherlands. Detailed measurements, including parental sensitivity, were obtained in a subgroup of children of Dutch national origin (the children, their parents, and their grandparents were all born in the Netherlands) to reduce confounding and effect modification (Tiemeier et al., 2012). The study was approved by the Medical Ethics Committee of the Erasmus Medical Centre. Written informed consent was obtained from all adult participants.

Resting-state functional MRI (rs-fMRI) and parental sensitivity scores were available for 147 children: for 134 children data on maternal sensitivity was available, while for 147 children paternal sensitivity scores were available. We excluded 23 children (16\%) due to poor quality rsfMRI data. Analyses regarding maternal sensitivity were performed on 112 children (57 girls), whereas analyses regarding paternal sensitivity were performed on 124 children (64 girls).

\section{Measures}


Sensitivity. Maternal and paternal sensitivity was observed when the children 4 years of age. Parents and children were observed during four 3- to 4-minute tasks that were too difficult for the child: building a tower and an etch-a-sketch task. Sessions were coded using the revised Erickson 7-point rating scales for Supportive presence and Intrusiveness (Egeland, Erickson, Clemenhagen-Moon, Hiester, \& Korfmacher, 1990). Overall sensitivity scores were created by aggregating the standardized subscale scores of both subscales in both tasks (reversing the Intrusiveness scores). The ICC was .84 (Kok et al., 2013). The correlation between fathers and mothers was .18. A composite parental sensitivity score was created by averaging the standardized maternal and paternal sensitivity scores, as was done in Kok et al., 2015, but maternal and paternal sensitivity were also analyzed separately. When results are stronger for the composite score than for the separate maternal and paternal sensitivity scores, this may suggest that the overall level of sensitivity experienced by the child is of greater importance than the sex of the parent providing care.

Covariates. Information on sex and date of birth was obtained from midwives and hospital registries. Intelligence (IQ) was estimated from the Mosaics and Categories subtest of the Snijders-Oomen Non-Verbal Intelligence Test-Revised when the children were on average six years old ( $M=108.42, S D=13.08)$ (Tellegen, Winkel, Wijnberg-Williams, \& Laros, 2005). IQ data was missing for 11 children. For these children, the score was imputed. Parental education was assessed via questionnaire when the children were on average 6 years of age. Parental education level was defined as the highest completed education and was categorized secondary (lower and intermediate vocational training, $n=28(23 \%)$ and $n=26(21 \%)$ for maternal and paternal education, respectively), and higher (higher vocational education and university, $n=96$ [73\%] and $n=98$ [71\%] for maternal and paternal education, respectively) education. 


\section{fMRI acquisition and processing}

Resting-state fMRI acquisition. The neuroimaging component of the Generation $\mathrm{R}$ Study has been presented in White et al., 2013. In brief, children were 6-to 10-years of age at the time of the MRI assessment $(M=8.04, S D=0.96)$. Prior to the MRI, the children were first familiarized with a mock scanning session. MRI scanning was performed on a GE Discovery MR 7503 T scanner (General Electric, Milwaukee, MI, USA) using an 8 channel head coil. Resting-state fMRI utilized a gradient-echo blood oxygen level dependent (BOLD) echo planar imaging (EPI) sequence with a TR $=2,000 \mathrm{~ms}, \mathrm{TE}=30 \mathrm{~ms}$, flip angle $=85^{\circ}$, matrix $64 \times 64$ and voxel resolution of $3.6 \times 3.6 \times 4.0 \mathrm{~mm} 3$. The total duration of the rs-fMRI session is $5 \mathrm{~min} .20 \mathrm{~s}$. (160 TRs). The children were asked to keep their eyes closed during the rs-fMRI sequence and to think about nothing in particular.

MR data pre-processing. Data were pre-processed using the Functional MRI of the Brain (FMRIB) Software Library (v5.0.5, FSL, http://fsl.fmrib.ox.ac.uk/fsl/fslwiki) (Jenkinson, Beckmann, Behrens, Woolrich, \& Smith, 2012). FSL's FMRI Expert Analysis Tool (FEAT) was used for preprocessing the rs-fMRI data, which consisted of exclusion of the first four volumes, motion correction, high-pass temporal filtering $(\sigma=50 \mathrm{~s})$, brain extraction, pre-whitening, and spatial filtering ( $F W H M=8 \mathrm{~mm}$ ). Registration of the rs-fMRI data to an in-house generated ageappropriate, standard space $\mathrm{T}_{1}$-weighted template was achieved using a two-step process. First, the RS-FMRI data were registered to the $\mathrm{T}_{1}$-weighted anatomical image with the FSL-Linear Registration Tool (FLIRT), using 6 degrees of freedom (DOF) and the boundary based registration (BBR) cost function. In the second stage, the $\mathrm{T}_{1}$-weighted image was registered to the age-appropriate, standard space $\mathrm{T}_{1}$-weighted template image using FLIRT with $12 \mathrm{DOF}$. The 
two resulting transformation matrices were concatenated and applied to the preprocessed rsfMRI data.

Given the age of the sample, it was important to use an age-appropriate template for registration of the functional data to standard space. One hundred thirty $\mathrm{T}_{1}$-weighted images from children without behavioral problems, also rated as having excellent quality, were used to construct the structural template for registration. An iterative approach using both linear and nonlinear algorithms was used (Sanchez, Richards, \& Almli, 2012), and is represented graphically in the supplemental data section (Figure 1). Briefly, $\mathrm{T}_{1}$-weighted images from each of the 130 subjects were first aligned to the MNI-152 1mm brain using a linear, 6 degree of freedom approach (FLIRT). All registered images were then averaged and used as the template brain for the subsequent step, which was a nonlinear registration (FNIRT). Once again, the result from the nonlinear registration was averaged and used as the template for the subsequent iteration. This routine continued for a total of five nonlinear iterations, where it has been shown the template image stabilizes considerably (Sanchez et al., 2012). The result of the fifth and final nonlinear registration was averaged, resampled to $2 \mathrm{~mm}$ isotropic resolution, and then used as the standard-space template for all rs-fMRI datasets.

Subject-level ICA-based artifact removal. In addition to standard fMRI pre-processing, each data set was cleaned to remove potential biases resulting from subject motion, cardiac/respiratory physiology, and scanner noise using the FMRIB ICA-based Xnoiseifier (FIX v1.06, Griffanti et al., 2014; Salimi-Khorshidi et al., 2014). With the aid of a training set, FIX automatically classifies subject-level ICA components as "signal" or "noise", and subsequently “denoises" the rs-fMRI data by regressing out time series classified as noise. A thorough and sophisticated cleaning procedure, such as FIX, is especially relevant in the context of pediatric 
rs-fMRI, given recent reports on the impact of motion on functional connectivity (Power, Barnes, Snyder, Schlaggar, \& Petersen, 2012; Satterthwaite et al., 2012). The FIX classifier was trained using manually labeled, subject-level ICA data from a random sample of 50 subjects (mean leave-one-out classifier performance results: 93.4\% true-positive rate, $85.8 \%$ true-negative rate). All rs-fMRI datasets underwent a single-session ICA using the Multivariate Exploratory Linear Optimized Decomposition into Independent Components (MELODIC, v5.0.5) tool from FSL, followed by the artifact removal with FIX, including the removal of motion confounds (Griffanti et al., 2014).

Data quality. Data quality was assessed in two steps. First, as the subject-level ICA denoising of the data is not sufficient in datasets severely corrupted by motion, a mean root-meansquared relative motion greater than $0.5 \mathrm{~mm}$ was used as a cutoff to exclude data of poor quality, $\mathrm{n}=19$ (13\%). Second, all standard space registrations were examined using the middle functional volume from the time-series, and poorly registered datasets were excluded, $\mathrm{n}=4$ $(3 \%)$.

\section{Statistical analyses}

The left and right amygdala masks from the Harvard-Oxford-subcortical atlas were used for analyses (Frazier et al., 2005). The mPFC mask was created by combining the medial frontal gyrus, medial orbitofrontal cortex and anterior cingulate cortex using Wake Forest University PickAtlas (Maldjian, Laurienti, Kraft, \& Burdette, 2003). The regions of interest were spatially normalized to the in-house template space by applying an inverse transform matrix from MNI template space to the in-house child template space. Amygdala functional connectivity was assessed at the single-subject level using the general linear model (GLM) within FSL(FEAT) with the time-series of the amygdalae (obtained using fslmeants) as the design matrix. 
Higher-level analyses were performed using FSL's FLAME I (FMRIB's local analysis of mixed effects) module to assess the interaction effect of parental sensitivity and age controlling for sensitivity, age, sex, sensitivity $\times$ sex and sex $\times$ age for the left and the right amygdala separately. In case of a significant interaction effect, analyses were repeated for maternal and paternal sensitivity scores separately. In exploratory analyses we assessed sensitivity $\times$ age $\times$ sex interaction effects (controlling for sensitivity, age, sex, sensitivity $\times$ age, sensitivity $\times$ sex and sex $\times$ age). All variables were mean-centered. Higher-level analyses were restricted to the voxels in the mPFC mask. Statistical maps were thresholded using clusters determined by $\mathrm{Z}>2.3$ and a cluster corrected significance threshold of $p<0.05$. In order to assure that results are specific to amygdala-mPFC connectivity, we repeated the higher-level analyses using a lateral PFC mask (superior frontal gyrus, middle frontal gyrus, inferior frontal gyrus from the WFU Pick Atlas).

In order to interpret significant interaction effects, we extracted mean $Z$-values of all significant voxels for all participants. Z-values were then imported into SPSS. Post-hoc analyses on interaction effects were conducted using the PROCESS SPSS custom dialog, using IQ and parental education as covariates.

\section{Results}

\section{Combined parental sensitivity}

Figure 2 and Table 1 show the clusters for which amygdala connectivity was significantly predicted by a parental sensitivity $\times$ age interaction effect. Post-hoc analyses (Tables 2,3 for full models and Table 4 for sensitivity $\times$ age interaction effects) showed that in children with lower combined parental sensitivity, amygdala-mPFC connectivity was related to age $(b=0.11, p=$ $.004, b=0.06, p=.06$, right and left amygdala, respectively). In children with highly sensitive 
parents, the association between right amygdala-mPFC connectivity and age was not significant ( $b=-0.7, p=.12, b=-0.06, p=.12$ right and left amygdala, respectively).

\section{Maternal sensitivity}

For the right amygdala, we found a significant maternal sensitivity $\times$ age interaction effect on amygdala - anterior cingulate cortex connectivity (Table 1 and Figure 2). Post-hoc analyses (Table 5 for full model, Table 4 for maternal sensitivity $\times$ age interaction effects) showed that in children from less sensitive mothers, right amygdala-mPFC connectivity increased over age $(b=0.09, p=.01)$. In children from more sensitive mothers, the association between right amygdala-mPFC connectivity and age was not significant $(b=-0.03, p=.52)$.

\section{Paternal sensitivity}

We did not find significant paternal sensitivity $\times$ age interaction effects on amygdalamPFC connectivity.

\section{Exploratory sensitivity $\times$ age $\times$ sex analyses}

Combined parental sensitivity. Table 6 and Figure 3 show the clusters for which amygdala connectivity was significantly predicted by a parental sensitivity $\times$ age $\times$ sex interaction effect. Table 7 shows the results of the post-hoc analyses of the parental sensitivity $\times$ age $\times$ sex interaction effect. In daughters from less sensitive parents, amygdala-mPFC connectivity was related to age $(b=0.26, p<.001, b=0.20, p<.001$ right and left amygdala, respectively). In daughters from highly sensitive parents, amygdala-mPFC decreased with age ( $b$ $=-0.12, p=.03, b=-0.10, p=.08$ right and left amygdala, respectively). In boys, no association between age and amygdala-mPFC connectivity was found (less sensitive parents $b=-0.05, p=$ $.34, b=-0.04, p=.36$ for right and left amygdala, respectively; highly sensitive parents $b=-$ $0.01, p=.94, b=0.07, p=.26$, for right and left amygdala, respectively). 
Maternal sensitivity. For the right amygdala, we found a significant maternal sensitivity $\times$ age $\times$ sex interaction effect on amygdala-mPFC functional connectivity. Specific information on the mPFC cluster in which this effect was found is presented in Table 6 and Figure 3. Posthoc analyses show that in daughters of less sensitive mothers amygdala-mPFC connectivity was related to age $(b=0.29, p<.001$, Table 7$)$. There was no association between age and amygdalamPFC connectivity in daughters from highly sensitive mothers $(b=-0.08, p=.17)$ or in sons $(b$ $=-0.04, p=.35$, and $b=-0.02, p=.80$ with less or highly sensitive mothers, respectively).

Paternal sensitivity. Table 6 and Figure 3 show the clusters for which amygdala connectivity was significantly predicted by a paternal sensitivity $\times$ age $\times$ sex interaction effect. Post-hoc analyses (Table 7) show that in daughters from less sensitive fathers, amygdala-mPFC connectivity was related to age $(b=0.23, p<.001$, and $b=0.18, p=.001$, right and left amygdala respectively). There was no association between age and amygdala-mPFC connectivity in daughters from more sensitive fathers $(b=-0.10, p=.10$, and $b=-0.07, p=.28$, for right and left amygdala respectively) or in sons (less sensitive fathers: $b=-0.04, p=.45$, and $b=-0.05, p=.36$, for right and left amygdala respectively, highly sensitive fathers: $(b=0.00, p$ $=.99$, and $b=0.10, p=.07$, for right and left amygdala respectively).

\section{Contrasting analyses: amygdala -lateral PFC connectivity.}

We did not find any combined parental sensitivity $\times$ age or combined parental sensitivity $\times$ age $\times$ sex interaction effects on amygdala - lateral PFC connectivity.

\section{Discussion}

In the present study we found that the association between age and amygdala-mPFC connectivity from age 6-to 10-years was modulated by normal variation in parental care. In children of less sensitive parents, age was related to stronger amygdala-mPFC connectivity, 
while in children from more sensitive parents, age was not associated with amygdala-mPFC connectivity. To our knowledge, the only study on amygdala resting-state functional connectivity that examined prepubertal children reported no evidence for connectivity between the amygdala and $\mathrm{mPFC}$ in children younger than 10.5 years, while for children older than 10.5 years, age was associated with stronger amygdala-mPFC connectivity (Gabard-Durnam et al., 2014). Our results, therefore, suggest that less sensitive parenting accelerates amygdala-mPFC circuit development. However, due to the age range of our sample, we are unable to test whether the increase in amygdala-mPFC coupling as displayed in children from less sensitive parents before the age of 10 years will also occur in children from highly sensitive parents after the age of 10 years.

Both animal and human research suggests that adverse caregiving experiences, such as maternal deprivation, may accelerate amygdala-mPFC connectivity (Callaghan \& Richardson, 2011; Gee, Gabard-Durnam, et al., 2013). Here, we show that in a population-based sample, variation in caregiving experience modulates the development of amygdala-mPFC coupling, such that lower levels of parental care seem to accelerate amygdala-mPFC circuit development. This suggests that even in family-reared children, those experiencing suboptimal parenting may prematurely activate the development of neural structures important for emotion regulation, which may enable them to self-regulate instead of needing to rely on their parents for emotion regulation.

Gee et al. (2013) showed that institutionalized children who display a more mature amygdala-mPFC are less anxious than children who display a more immature amygdala-mPFC connectivity pattern, but are still more anxious than their family-reared peers. Thus, the more mature amygdala-mPFC connectivity pattern of children from less sensitive parents may support 
their regulation capacities, but they are still generally less well-regulated than children who experienced more sensitive care (Manning et al., 2014; Van der Voort et al., 2014). Life history theory predicts accelerated neurobiological development in children and pre-adolescents from less privileged backgrounds who have to be prepared for adaptation to non-optimal environments by using a fast reproductive strategy (Hochberg \& Belsky, 2013). Neurobiological and behavioral development might not be synchronized at all developmental time-points, and in some cases neurobiological changes might prepare behavioral adaptations that seem to lag behind, a form of developmental 'decalage' (Van IJzendoorn, Juffer \& Poelhuis, 2005).

When the quality of parental care is low, it may be beneficial to switch from parentregulated emotional control to self-regulated emotional control. In the long term, however, early termination of the immature period may have negative consequences (Callaghan and Tottenham, 2016b). A long childhood period is beneficial for development. For example, a prolonged period of cortical thickness growth has been associated with superior intelligence in children (Shaw et al., 2006). Low levels of parental care may terminate the immature period before the circuit has acquired the characteristics necessary for adequate self-regulatory control. Indeed, early life stress has been associated with increased amygdala-mPFC resting-state connectivity in adulthood (Philip et al., 2013). In adults, aberrant amygdala-mPFC functional connectivity has been associated with anxiety and depression (Hahn et al., 2011; Townsend et al., 2013), psychological problems which are more prevalent in individuals with adverse caregiving experiences (Norman et al., 2012).

One way in which parental care may influence development of the amygdala-mPFC circuit is via regulation of a sensitive period of plasticity (Callaghan \& Tottenham, 2016a). Within the visual system, the balance between excitatory and inhibitory signaling appears to 
regulate the onset of sensitive period plasticity. Continued development then results in formation of structural brakes that terminate the sensitive period (Hensch, 2004). In the case of amygdalamPFC development, child caregiver independence may regulate the sensitive period for environmental input. Callaghan and Tottenham (2016a) suggest that during childhood, relative caregiver dependence may allow for environmental input in the amygdala-mPFC circuit. Over development, the child's independence grows which may cause the sensitive period to close. When the child reaches independence early in development, this may prematurely close the sensitive period, resulting in accelerated development of the amygdala-mPFC circuit (Callaghan \& Tottenham, 2016a).

Our exploratory analyses suggest that parental sensitivity affects the development of amygdala-mPFC connectivity in daughters only. Compared to boys, girls may generally rely more on others for emotion regulation (Quiroga, Willis, Lopez-Rodriguez, \& Moreno, 2015; Zimmermann \& Iwanski, 2014). If this is true, the effect of parental care on the development of neural networks associated with emotion regulation may be expected to be larger in girls than in boys. However, there is also evidence suggesting that compared to boys, girls are more likely to seek contact to mother and stay in closer proximity to her regardless of distress, while boys' proximity seeking is associated with distress specifically (Buss, Brooker, \& Leuty, 2008). Alternatively, the different effect of parental sensitivity on sons' and daughters' amygdala-mPFC circuit development may be explained by sex differences in neurodevelopment. The social brain has been reported to develop earlier in girls than in boys (Mutlu et al., 2013). It is, therefore, possible that in boys the interaction effect of parental sensitivity and age occurs later in development and was thus not visible in the present sample. Moreover, although Gabard-Durnam et al. (2014) reported no sex differences in amygdala-mPFC connectivity development, one study 
suggests that in adolescent girls, amygdala-dorsal mPFC connectivity increased with age, while in adolescent boys amygdala-ventral mPFC connectivity increased with age (Alarcon, Cservenka, Rudolph, Fair, \& Nagel, 2015). Although we did not find such evidence in our study, a similar moderating effect of sensitivity on amygdala-mPFC circuit development may be evident in boys, but in a different region of the mPFC.

The results of the exploratory three-way interaction analyses are only partly in accordance with our hypothesis. Consistent with the sex-controlled analyses, daughters of less sensitive parents show an increase in functional connectivity over age. However, contrary to our hypothesis, daughters from highly sensitive parents show a decrease in functional connectivity over age. One possible explanation for this unexpected finding is that the regions we find are located somewhat more dorsally than the regions reported in the Gabard-Durnam et al. (2014) and Gee et al. (2013) studies. The development of amygdala-mPFC connectivity in this specific region may follow a different trajectory. Moreover, as three-way interactions require large sample sizes, the present study may not have enough power to properly examine three-way interaction effects. Results of the three-way interaction analyses should thus be regarded as exploratory and await replication.

Studies on caregiving and child development tend to focus on the role of mothers more so than on the role of fathers. In the present study, the sensitivity $\times$ age interaction effect for the combined parental sensitivity measure had a smaller $p$-value (on face value) than the interaction effect for the maternal sensitivity measure, implying that both maternal and paternal sensitivity contribute to the observed effect. Moreover, results of the exploratory three-way interaction analysis suggest similar effects for mothers and fathers. Our results, therefore, imply that the quality of parental caregiving is more important for brain development than sex of the person 
providing this care. However, statistical tests to examine the significance of the difference in maternal versus paternal contributions to the connectivity are difficult to conduct on imaging data, and power constraints prohibited adding parent gender as an additional interaction term. These considerations need to be taken into account, and make our suggestions speculative.

Several limitations should be noted. The present study is based on cross-sectional MRI data, with sensitivity assessed 2- to-6 years earlier. Although such studies can provide information on development, longitudinal studies with both variables measured at both time points are of course better equipped to answer developmental questions. As we are unable to test whether children from more sensitive parents will show a similar increase in amygdala-mPFC coupling after the age of 10 years as displayed by children from less sensitive parents before the age of 10 years, assumptions about accelerated development are made based on the literature and cannot be conclusively inferred from our own data. Finally, resting-state fMRI data were collected for 5 minutes and 20 seconds. While a 5- to 6-minute acquisition time should provide adequate sampling to produce stable spatial maps even in children (White et al., 2014), longer acquisition time are better to distinguish subtle individual differences in the strength of functional connections within networks (Birn et al., 2013).

Although our findings are preliminary, they point to potentially fruitful directions for the study of the long-term effects of attachment-based interventions aiming at the enhancement of parental sensitivity. Previous studies have shown that attachment-based interventions can get 'under the skin', which might explain the persistence of their influence on the parents and their children. For example, Dozier, Peloso, Lewis, Laurenceau, and Levine (2008) found that their Attachment and Bio-behavioral Catch-up (ABC) intervention led to a reduction in basal cortisol in children in foster care. In a sensitivity-focused video-feedback intervention (VIPP-SD) for 
toddlers at risk of behavioral problems, Bakermans-Kranenburg, Van IJzendoorn, Pijlman, Mesman, and Juffer (2008) also found long-term improvement of cortisol regulation, in particular in carriers of DRD4-7R alleles. Cortisol secretion is regulated in brain regions such as the hippocampus and the search for attachment-based intervention effects on brain structure, connectivity, and function might shed further light on the cascade of neurobiological changes in children participating in such interventions even if the intervention effects are relatively small, and certainly not as dramatic as the influence of adoption or foster care of previously institutionalized children (Nelson, Fox, Zeanah, 2015 book). Our non-experimental, correlational study with typically developing children and their parents may be considered a first step toward elucidating this cascade in clinical and non-clinical populations (see also Fearon et al., 2016).

In conclusion, the present population-based study suggests that parenting quality may moderate the development of amygdala-mPFC coupling. Not only extreme caregiving experiences, but also normal variation in caregiving appears to be associated with development of amygdala-mPFC functional connectivity. The present study provides insight into how children adapt their developmental strategies to suboptimal parental care, which may shed light on the mechanisms through which suboptimal parental care increases the risk of emotional problems and psychopathology. 


\section{References}

Ainsworth, M. D. \& Bell, S. M. (1970). Attachment, exploration, and separation: illustrated by the behavior of one-year-olds in a strange situation. Child Development, 41, 49-67.

Ainsworth, M. S., Bell, S. M. \& Stayton, D. J. (1974). Infant-mother attachment and social development: 'socialization' as a product of reciprocal responsiveness to signals. In M.P.M. Richards (Ed.) The integration of a child into a social world (pp. 99-135). London: Cambridge University Press.

Akirav, I. \& Maroun, M. (2007). The role of the medial prefrontal cortex-amygdala circuit in stress effects on the extinction of fear. Neural Plasticity, 2007, 30873.

Alarcon, G., Cservenka, A., Rudolph, M. D., Fair, D. A. \& Nagel, B. J. (2015). Developmental sex differences in resting state functional connectivity of amygdala sub-regions. Neuroimage, 115, 235-44.

Bakermans-Kranenburg, M. J., Van, I. M. H., Pijlman, F. T., Mesman, J. \& Juffer, F. (2008). Experimental evidence for differential susceptibility: dopamine D4 receptor polymorphism (DRD4 VNTR) moderates intervention effects on toddlers' externalizing behavior in a randomized controlled trial. Developmental Psychology, 44, 293-300.

Banihashemi, L., Sheu, L. K., Midei, A. J. \& Gianaros, P. J. (2015). Childhood physical abuse predicts stressor-evoked activity within central visceral control regions. Social Cognitive and Affective Neuroscience, 10, 474-85.

Belsky, J., Ruttle, P. L., Boyce, W. T., Armstrong, J. M. \& Essex, M. J. (2015). Early adversity, elevated stress physiology, accelerated sexual maturation, and poor health in females. Developmental Psychology, 51, 816-22. 
Belsky, J., Steinberg, L. \& Draper, P. (1991). Childhood experience, interpersonal development, and reproductive strategy - an evolutionary-theory of socialization. Child Development, $62,647-70$.

Bernier, A., Carlson, S. M., Deschenes, M. \& Matte-Gagne, C. (2012). Social factors in the development of early executive functioning: a closer look at the caregiving environment. Developmental Science, 15, 12-24.

Birn, R. M., Molloy, E. K., Patriat, R., Parker, T., Meier, T. B., Kirk, G. R., Nair, V. A., Meyerand, M. E. \& Prabhakaran, V. (2013). The effect of scan length on the reliability of resting-state fMRI connectivity estimates. Neuroimage, $83,550-8$.

Buss, K. A., Brooker, R. J. \& Leuty, M. (2008). Girls most of the time, boys some of the time: Gender differences in toddlers' use of maternal proximity and comfort seeking. Infancy, $13,1-29$.

Callaghan, B. L. \& Richardson, R. (2011). Maternal separation results in early emergence of adult-like fear and extinction learning in infant rats. Behavioral Neuroscience, 125, 20-8.

Callaghan, B. L. \& Tottenham, N. (2016a). The neuro-environmental loop of plasticity: A crossspecies analysis of parental effects on emotion circuitry development following typical and adverse caregiving. Neuropsychopharmacology, 41, 163-76.

Callaghan, B. L. \& Tottenham, N. (2016b). The stress acceleration hypothesis: effects of earlylife adversity on emotion circuits and behavior. Current Opinions in Behavioral Sciences, 7, 76-81.

Cicchetti, D. (2016). Developmental Psychopathology. Hoboken, New Jersey: John Wiley \& Sons. 
Conner, O. L., Siegle, G. J., McFarland, A. M., Silk, J. S., Ladouceur, C. D., Dahl, R. E., Coan, J. A. \& Ryan, N. D. (2012). Mom-it helps when you're right here! Attenuation of neural stress markers in anxious youths whose caregivers are present during fMRI. PLoS One, 7, e50680.

Dannlowski, U., Kugel, H., Huber, F., Stuhrmann, A., Redlich, R., Grotegerd, D., Dohm, K., Sehlmeyer, C., Konrad, C., Baune, B. T., Arolt, V., Heindel, W., Zwitserlood, P. \& Suslow, T. (2013). Childhood maltreatment is associated with an automatic negative emotion processing bias in the amygdala. Human Brain Mapping, 34, 2899-909.

Decety, J., Michalska, K. J. \& Kinzler, K. D. (2012). The contribution of emotion and cognition to moral sensitivity: a neurodevelopmental study. Cerebral Cortex, 22, 209-20.

Dozier, M., Peloso, E., Lewis, E., Laurenceau, J. P. \& Levine, S. (2008). Effects of an attachment-based intervention on the cortisol production of infants and toddlers in foster care. Development and Psychopatholy, 20, 845-59.

Dujardin, A., Bosmans, G., De Raedt, R. \& Braet, C. (2015). Children's attentional exploration of threatening information as related to trust in maternal support. Developmental Psychology, 51, 1341-50.

Egeland, B., Erickson, M. F., Clemenhagen-Moon, J., Hiester, M. K. \& Korfmacher, J. (1990). 24 months tool coding manual. Project STEEP-revised 1990 from mother-child project scales. University of Minnesota, Minneapolis, MN, USA.

Ellis, B. J., Schlomer, G. L., Tilley, E. H. \& Butler, E. A. (2012). Impact of fathers on risky sexual behavior in daughters: A genetically and environmentally controlled sibling study. Development and Psychopathology, 24, 317-32. 
Fearon, R. M. P., Groh, A. M., Van IJzendoorn, M. H., Bakermans-Kranenburg, M. J. \& Roisman, G. I. (2016). Attachment and developmental psychopathology. In D. Cicchetti (Ed.) Developmental Psychopathology (pp. 325-84). Hoboken, New Jersey: John Wiley \& Sons.

Forbes, C. E. \& Grafman, J. (2010). The Role of the Human Prefrontal Cortex in Social Cognition and Moral Judgment. Annual Review of Neuroscience, Vol 33, 33, 299-324.

Frazier, J. A., Chiu, S. F., Breeze, J. L., Makris, N., Lange, N., Kennedy, D. N., Herbert, M. R., Bent, E. K., Koneru, V. K., Dieterich, M. E., Hodge, S. M., Rauch, S. L., Grant, P. E., Cohen, B. M., Seidman, L. J., Caviness, V. S. \& Biederman, J. (2005). Structural brain magnetic resonance imaging of limbic and thalamic volumes in pediatric bipolar disorder. American Journal of Psychiatry, 162, 1256-65.

Gabard-Durnam, L. J., Flannery, J., Goff, B., Gee, D. G., Humphreys, K. L., Telzer, E., Hare, T. \& Tottenham, N. (2014). The development of human amygdala functional connectivity at rest from 4 to 23 years: A cross-sectional study. Neuroimage, 95, 193-207.

Gee, D. G., Gabard-Durnam, L. J., Flannery, J., Goff, B., Humphreys, K. L., Telzer, E. H., Hare, T. A., Bookheimer, S. Y. \& Tottenham, N. (2013a). Early developmental emergence of human amygdala-prefrontal connectivity after maternal deprivation. Proceedings of the National Academy of Sciences of the United States of America, 110, 15638-43.

Gee, D. G., Humphreys, K. L., Flannery, J., Goff, B., Telzer, E. H., Shapiro, M., Hare, T. A., Bookheimer, S. Y. \& Tottenham, N. (2013b). A developmental shift from positive to negative connectivity in human amygdala-prefrontal circuitry. Journal of Neuroscience, $33,4584-93$. 
Giedd, J. N., Vaituzis, A. C., Hamburger, S. D., Lange, N., Rajapakse, J. C., Kaysen, D., Vauss, Y. C. \& Rapoport, J. L. (1996). Quantitative MRI of the temporal lobe, amygdala, and hippocampus in normal human development: Ages 4-18 years. Journal of Comparative Neurology, 366, 223-30.

Griffanti, L., Salimi-Khorshidi, G., Beckmann, C. F., Auerbach, E. J., Douaud, G., Sexton, C. E., Zsoldos, E., Ebmeier, K. P., Filippini, N., Mackay, C. E., Moeller, S., Xu, J., Yacoub, E., Baselli, G., Ugurbil, K., Miller, K. L. \& Smith, S. M. (2014). ICA-based artefact removal and accelerated fMRI acquisition for improved resting state network imaging. Neuroimage, 95, 232-47.

Guyer, A. E., Monk, C. S., McClure-Tone, E. B., Nelson, E. E., Roberson-Nay, R., Adler, A. D., Fromm, S. J., Leibenluft, E., Pine, D. S. \& Ernst, M. (2008). A developmental examination of amygdala response to facial expressions. Journal of Cognitive Neuroscience, 20, 1565-82.

Hahn, A., Stein, P., Windischberger, C., Weissenbacher, A., Spindelegger, C., Moser, E., Kasper, S. \& Lanzenberger, R. (2011). Reduced resting-state functional connectivity between amygdala and orbitofrontal cortex in social anxiety disorder. Neuroimage, 56, $881-9$.

Hariri, A. R., Mattay, V. S., Tessitore, A., Fera, F. \& Weinberger, D. R. (2003). Neocortical modulation of the amygdala response to fearful stimuli. Biological Psychiatry, 53, 494501.

Hensch, T. K. (2004). Critical period regulation. Annual Review of Neuroscience, 27, 549-79. Hochberg, Z. \& Belsky, J. (2013). Evo-devo of human adolescence: beyond disease models of early puberty. BMC Medicine, 11 . 
Hostinar, C. E., Johnson, A. E. \& Gunnar, M. R. (2015). Early social deprivation and the social buffering of cortisol stress responses in late childhood: An experimental study. Developmental Psychology, 51, 1597-608.

Jaddoe, V. W., van Duijn, C. M., Franco, O. H., van der Heijden, A. J., van IJzendoorn, M. H., de Jongste, J. C., van der Lugt, A., Mackenbach, J. P., Moll, H. A., Raat, H., Rivadeneira, F., Steegers, E. A., Tiemeier, H., Uitterlinden, A. G., Verhulst, F. C. \& Hofman, A. (2012). The Generation R Study: design and cohort update 2012. European Journal of Epidemiology, 27, 739-56.

Jenkinson, M., Beckmann, C. F., Behrens, T. E., Woolrich, M. W. \& Smith, S. M. (2012). Fsl. Neuroimage, 62, 782-90.

Kok, R., Linting, M., Bakermans-Kranenburg, M. J., van IJzendoorn, M. H., Jaddoe, V. W. V., Hofman, A., Verhulst, F. C. \& Tiemeier, H. (2013a). Maternal sensitivity and internalizing problems: evidence from two longitudinal studies in early childhood. Child Psychiatry \& Human Development, 44, 751-65.

Kok, R., Thijssen, S., Bakernnans-Kranenburg, M. J., Jaddoe, V. W. V., Verhulst, F. C., White, T., van IJzendoorn, M. H. \& Tiemeier, H. (2015). Normal variation in early parental sensitivity predicts child structural brain development. Journal of the American Academy of Child and Adolescent Psychiatry, 54, 824-31.

Kok, R., van IJzendoorn, M. H., Linting, M., Bakermans-Kranenburg, M. J., Tharner, A., Luijk, M. P. C. M., Szekely, E., Jaddoe, V. W. V., Hofman, A., Verhulst, F. C. \& Tiemeier, H. (2013b). Attachment insecurity predicts child active resistance to parental requests in a compliance task. Child Care Health and Development, 39, 277-87. 
Lucassen, N., Kok, R., Bakermans-Kranenburg, M. J., Van Ijzendoorn, M. H., Jaddoe, V. W. V., Hofman, A., Verhulst, F. C., Lambregtse-Van den Berg, M. P. \& Tiemeier, H. (2015). Executive functions in early childhood: The role of maternal and paternal parenting practices. British Journal of Developmental Psychology, 33, 489-505.

Maldjian, J. A., Laurienti, P. J., Kraft, R. A. \& Burdette, J. H. (2003). An automated method for neuroanatomic and cytoarchitectonic atlas-based interrogation of fMRI data sets. Neuroimage, 19, 1233-9.

Manning, L. G., Davies, P. T. \& Cicchetti, D. (2014). Interparental violence and childhood adjustment: how and why maternal sensitivity is a protective factor. Child Development, $85,2263-78$.

Mehta, M. A., Golembo, N. I., Nosarti, C., Colvert, E., Mota, A., Williams, S. C. R., Rutter, M. \& Sonuga-Barke, E. J. S. (2009). Amygdala, hippocampal and corpus callosum size following severe early institutional deprivation: The English and Romanian Adoptees Study Pilot. Journal of Child Psychology and Psychiatry, 50, 943-51.

Miller, E. K. (2002). The prefrontal cortex and cognitive control. Perception, 31, 104-.

Moriceau, S. \& Sullivan, R. M. (2006). Maternal presence serves as a switch between learning fear and attraction in infancy. Nature Neuroscience, 9, 1004-6.

Moutsiana, C., Johnstone, T., Murray, L., Fearon, P., Cooper, P. J., Pliatsikas, C., Goodyer, I. \& Halligan, S. L. (2015). Insecure attachment during infancy predicts greater amygdala volumes in early adulthood. Journal of Child Psychology and Psychiatry, 56, 540-8.

Mutlu, A. K., Schneider, M., Debbane, M., Badoud, D., Eliez, S. \& Schaer, M. (2013). Sex differences in thickness, and folding developments throughout the cortex. Neuroimage, $82,200-7$. 
Nelson, C. A., Fox, N. A. \& Zeanah, C. H. (2014). Romania's Abandoned Children: deprivation, brain development, and the struggle for recovery. Cambridge, MA: Harvard University Press.

Newton, E. K., Laible, D., Carlo, G., Steele, J. S. \& McGinley, M. (2014). Do sensitive parents foster kind children, or vice versa? Bidirectional influences between children's prosocial behavior and parental sensitivity. Developmental Psychology, 50, 1808-16.

Norman, R. E., Byambaa, M., De, R., Butchart, A., Scott, J. \& Vos, T. (2012). The long-term health consequences of child physical abuse, emotional abuse, and neglect: a systematic review and meta-analysis. Plos Medicine, 9.

Ochsner, K. N., Bunge, S. A., Gross, J. J. \& Gabrieli, J. D. E. (2002). Rethinking feelings: An fMRI study of the cognitive regulation of emotion. Journal of Cognitive Neuroscience, $14,1215-29$.

Olsavsky, A. K., Telzer, E. H., Shapiro, M., Humphreys, K. L., Flannery, J., Goff, B. \& Tottenham, N. (2013). Indiscriminate amygdala response to mothers and strangers after early maternal deprivation. Biological Psychiatry, 74, 853-60.

Perlman, S. B. \& Pelphrey, K. A. (2011). Developing connections for affective regulation: Agerelated changes in emotional brain connectivity. Journal of Experimental Child Psychology, 108, 607-20.

Phan, K. L., Fitzgerald, D. A., Nathan, P. J., Moore, G. J., Uhde, T. W. \& Tancer, M. E. (2005). Neural substrates for voluntary suppression of negative affect: A functional magnetic resonance imaging study. Biological Psychiatry, 57, 210-9.

Phelps, E. A. \& LeDoux, J. E. (2005). Contributions of the amygdala to emotion processing: From animal models to human behavior. Neuron, 48, 175-87. 
Philip, N. S., Sweet, L. H., Tyrka, A. R., Price, L. H., Bloom, R. F. \& Carpenter, L. L. (2013). Decreased default network connectivity is associated with early life stress in medicationfree healthy adults. European Neuropsychopharmacology, 23, 24-32.

Power, J. D., Barnes, K. A., Snyder, A. Z., Schlaggar, B. L. \& Petersen, S. E. (2012). Spurious but systematic correlations in functional connectivity MRI networks arise from subject motion. Neuroimage, 59, 2142-54.

Quiroga, A., Willis, G. B., Lopez-Rodriguez, L. \& Moreno, A. (2015). Psychological consequences of collective violence in childhood: the case of Monterrey, Mexico. Estudios De Psicologia, 36, 294-315.

Rijlaarsdam, J., Stevens, G. W. J. M., van der Ende, J., Hofman, A., Jaddoe, V. W. V., Mackenbach, J. P., Verhulst, F. C. \& Tiemeier, H. (2013). Economic disadvantage and young children's emotional and behavioral problems: mechanisms of risk. Journal of Abnormal Child Psychology, 41, 125-37.

Salimi-Khorshidi, G., Douaud, G., Beckmann, C. F., Glasser, M. F., Griffanti, L. \& Smith, S. M. (2014). Automatic denoising of functional MRI data: Combining independent component analysis and hierarchical fusion of classifiers. Neuroimage.

Sanchez, C. E., Richards, J. E. \& Almli, C. R. (2012). Age-specific MRI templates for pediatric neuroimaging. Developmental Neuropsychology, 37, 379-99.

Satterthwaite, T. D., Wolf, D. H., Loughead, J., Ruparel, K., Elliott, M. A., Hakonarson, H., Gur, R. C. \& Gur, R. E. (2012). Impact of in-scanner head motion on multiple measures of functional connectivity: relevance for studies of neurodevelopment in youth. Neuroimage, 60, 623-32. 
Seltzer, L. J., Prososki, A. R., Ziegler, T. E. \& Pollak, S. D. (2012). Instant messages vs. speech: hormones and why we still need to hear each other. Evolution and Human Behavior, 33, $42-5$.

Shaw, P., Greenstein, D., Lerch, J., Clasen, L., Lenroot, R., Gogtay, N., Evans, A., Rapoport, J. \& Giedd, J. (2006). Intellectual ability and cortical development in children and adolescents. Nature, 440, 676-9.

Shaw, P., Kabani, N. J., Lerch, J. P., Eckstrand, K., Lenroot, R., Gogtay, N., Greenstein, D., Clasen, L., Evans, A., Rapoport, J. L., Giedd, J. N. \& Wise, S. P. (2008). Neurodevelopmental trajectories of the human cerebral cortex. Journal of Neuroscience, $28,3586-94$.

Sroufe, L. A. (1990). Considering normal and abnormal together: The essence of developmental psychopathology. Development and Psychopathology, 2, 335-47.

Tellegen, P. J., Winkel, M., Wijnberg-Williams, B. \& Laros, J. A. (2005). Snijders-Oomen NietVerbale Intelligentietest: SON-R 2 1/2 - 7. Amsterdam: Boom Testuitgevers.

Tiemeier, H., Velders, F. P., Szekely, E., Roza, S. J., Dieleman, G., Jaddoe, V. W., Uitterlinden, A. G., White, T. J., Bakermans-Kranenburg, M. J., Hofman, A., Van Ijzendoorn, M. H., Hudziak, J. J. \& Verhulst, F. C. (2012). The Generation R Study: A review of design, findings to date, and a study of the 5-HTTLPR by environmental interaction from fetal life onward. Journal of the American Acadamy of Child and Adolescent Psychiatry, 51, 1119-35 e7.

Tottenham, N. (2015). Social scaffolding of human amygdala-mPFCcircuit development. Social Neuroscience, 10, 489-99. 
Tottenham, N., Hare, T. A., Quinn, B. T., McCarry, T. W., Nurse, M., Gilhooly, T., Millner, A., Galvan, A., Davidson, M. C., Eigsti, I. M., Thomas, K. M., Freed, P. J., Booma, E. S., Gunnar, M. R., Altemus, M., Aronson, J. \& Casey, B. J. (2010). Prolonged institutional rearing is associated with atypically large amygdala volume and difficulties in emotion regulation. Developmental Science, 13, 46-61.

Townsend, J. D., Torrisi, S. J., Lieberman, M. D., Sugar, C. A., Bookheimer, S. Y. \& Altshuler, L. L. (2013). Frontal-amygdala connectivity alterations during emotion downregulation in bipolar i disorder. Biological Psychiatry, 73, 127-35.

van der Voort, A., Linting, M., Juffer, F., Bakermans-Kranenburg, M. J., Schoenmaker, C. \& van IJzendoorn, M. H. (2014). The development of adolescents' internalizing behavior: longitudinal effects of maternal sensitivity and child inhibition. Journal of Youth Adolescence, 43, 528-40.

van IJzendoorn, M. H., Juffer, F. \& Poelhuis, C. W. (2005). Adoption and cognitive development: a meta-analytic comparison of adopted and nonadopted children's IQ and school performance. Psychological Bulletin, 131, 301-16.

White, T., El Marroun, H., Nijs, I., Schmidt, M., van der Lugt, A., Wielopolki, P. A., Jaddoe, V. W., Hofman, A., Krestin, G. P., Tiemeier, H. \& Verhulst, F. C. (2013). Pediatric population-based neuroimaging and the Generation R Study: the intersection of developmental neuroscience and epidemiology. European Journal of Epidemiology, 28, 99-111.

White, T., Muetzel, R., Schmidt, M., Langeslag, S. J., Jaddoe, V., Hofman, A., Calhoun, V. D., Verhulst, F. C. \& Tiemeier, H. (2014). Time of acquisition and network stability in 
pediatric resting-state functional magnetic resonance imaging. Brain Connectivity, 4, 417-27.

Whittle, S., Simmons, J. G., Dennison, M., Vijayakumar, N., Schwartz, O., Yap, M. B. H., Sheeber, L. \& Allen, N. B. (2014). Positive parenting predicts the development of adolescent brain structure: A longitudinal study. Developmental Cognitive Neuroscience, 8, 7-17.

Whittle, S., Yap, M. B. H., Yucel, M., Sheeber, L., Simmons, J. G., Pantelis, C. \& Allen, N. B. (2009). Maternal responses to adolescent positive affect are associated with adolescents' reward neuroanatomy. Social Cognitive and Affective Neuroscience, 4, 247-56.

Wu, R. Y., Song, Z. Z., Wang, S. Y., Shui, L., Tai, F. D., Qiao, X. F. \& He, F. Q. (2014). Early paternal deprivation alters levels of hippocarnpal brain-derived neurotrophic factor and glucocorticold receptor and serum corticosterone and adrenocorticotropin in a sexspecific way in socially monogamous mandarin voles. Neuroendocrinology, 100, 119-28.

Yu, P., An, S. C., Tai, F. D., Zhang, X., He, F. Q., Wang, J. L., An, X. L. \& Wu, R. Y. (2012). The effects of neonatal paternal deprivation on pair bonding, NAcc dopamine receptor mRNA expression and serum corticosterone in mandarin voles. Hormones and Behavior, $61,669-77$.

Zimmermann, P. \& Iwanski, A. (2014). Emotion regulation from early adolescence to emerging adulthood and middle adulthood Age differences, gender differences, and emotionspecific developmental variations. International Journal of Behavioral Development, 38, 182-94. 
Table 1

Sensitivity $\times$ age effects on amygdala-mPFC functional connectivity

\section{MNI coordinates}

\begin{tabular}{|c|c|c|c|c|c|c|c|}
\hline \multirow[b]{2}{*}{ Cluster } & \multirow[b]{2}{*}{ Region } & \multirow[b]{2}{*}{ Size } & \\
\hline & & & $\mathrm{x}$ & $\mathrm{y}$ & $\mathrm{z}$ & $z$ & $p$ \\
\hline \multicolumn{8}{|c|}{ Parental sensitivity - Right amygdala } \\
\hline \multirow[t]{6}{*}{1} & $\mathrm{R} \mathrm{WM} / \mathrm{ACC}$ & 1522 & 16 & 32 & 19 & 3.89 & $<.001$ \\
\hline & $\mathrm{LACC}$ & & -9 & 28 & 21 & 3.79 & \\
\hline & $\mathrm{R}$ paracingulate gyrus & & 16 & 38 & 19 & 3.68 & \\
\hline & $\mathrm{LACC}$ & & -4 & 21 & 25 & 3.64 & \\
\hline & $\mathrm{R} \mathrm{WM} / \mathrm{ACC}$ & & 9 & 28 & 19 & 3.62 & \\
\hline & $\mathrm{L} \mathrm{WM} / \mathrm{ACC}$ & & -9 & 13 & 25 & 3.47 & \\
\hline
\end{tabular}

Parental sensitivity -Left amygdala

\begin{tabular}{|c|c|c|c|c|c|c|c|}
\hline 1 & $\mathrm{R} A C C$ & 690 & 5 & 28 & 19 & 3.60 & .02 \\
\hline & L WM/ACC & & -9 & 13 & 25 & 3.59 & \\
\hline & L WM/paracingulate gyrus & & -16 & 32 & 25 & 3.55 & \\
\hline & $\mathrm{L} A C C$ & & -7 & 25 & 21 & 3.54 & \\
\hline & $\mathrm{L} A C C$ & & -4 & 30 & 19 & 3.51 & \\
\hline & $\mathrm{L} A C C$ & & -7 & 8 & 27 & 3.49 & \\
\hline & sensitivity - Right amygdale & & & & & & \\
\hline 1 & $\mathrm{R}$ paracingulate gyrus & 438 & 18 & 38 & 16 & 4.02 & .04 \\
\hline & $\mathrm{L} A C C$ & & -7 & 30 & 16 & 3.13 & \\
\hline & $\mathrm{L} A C C$ & & -7 & 13 & 25 & 3.10 & \\
\hline
\end{tabular}




\begin{tabular}{lllll}
\hline L ACC & -13 & 34 & 19 & 2.95 \\
L ACC & -9 & 4 & 30 & 2.94 \\
WM & 13 & 32 & 5 & 2.89
\end{tabular}

Note. Results of the general linear model of the sensitivity $\times$ age interaction effects on amygdalamPFC functional connectivity. $\mathrm{WM}=$ white matter, $\mathrm{ACC}=$ anterior cingulate cortex 
Table 2

Full model of parental sensitivity $\times$ age interaction effect on right amygdala-mPFC connectivity

\begin{tabular}{lllllll}
\hline \multicolumn{1}{c}{$r$} & $r^{2}$ & $M S E$ & $F$ & $d f 1$ & $d f 2$ & $p$ \\
\hline \multicolumn{1}{c}{.14} & .09 & 2.76 & 7 & 116 & .01 \\
\hline Constant & $b$ & $S E$ & $t$ & $p$ & $L L C I$ & $U L C I$ \\
Gender & 0.47 & 0.26 & 1.79 & .08 & -0.05 & 0.99 \\
IQ & 0.07 & 0.05 & 1.37 & .17 & -0.03 & 0.18 \\
Paternal education & 0.00 & 0.00 & 0.20 & .84 & -0.00 & 0.00 \\
Maternal education & -0.08 & 0.07 & -1.16 & .25 & -0.22 & 0.06 \\
Parental sensitivity & -0.03 & 0.07 & -0.37 & .71 & -0.16 & 0.11 \\
Age rs-fMRI & 0.04 & 0.05 & 0.88 & .38 & -0.05 & 0.14 \\
Parental sensitivity $\times$ age & -0.15 & 0.05 & -2.96 & .004 & -0.26 & -0.05 \\
& & & & & & \\
\end{tabular}

Note. Results of the PROCESS regression analysis examining the parental sensitivity $\times$ age interaction effect on right amygdala-mPFC connectivity. The top row of the table describes the model characteristics, while the lower rows describe characteristics of the dependent variables. LLCI = lower limit confidence interval; ULCI = upper limit confidence interval 
Table 3

Full model of parental sensitivity $\times$ age interaction effect on left amygdala-mPFC connectivity

\begin{tabular}{lllllll}
\hline \multicolumn{1}{c}{$r$} & $r^{2}$ & $M S E$ & $F$ & $d f 1$ & $d f 2$ & $p$ \\
\hline \multicolumn{1}{c}{.10} & .06 & 1.83 & 7 & 116 & .09 \\
\hline Constant & $b$ & $S E$ & $t$ & $p$ & $L L C I$ & $U L C I$ \\
Gender & 0.38 & 0.22 & 1.70 & .09 & -0.06 & 0.83 \\
IQ & 0.04 & 0.05 & 0.92 & .36 & -0.05 & 0.13 \\
Paternal education & 0.00 & 0.00 & 0.15 & .88 & -0.00 & 0.00 \\
Maternal education & -0.04 & 0.06 & -0.70 & .48 & -0.17 & 0.08 \\
Parental sensitivity & -0.04 & 0.06 & -0.06 & .53 & -0.16 & 0.08 \\
Age rs-fMRI & 0.05 & 0.02 & 1.21 & .23 & -0.03 & 0.14 \\
Parental sensitivity $\times$ age & -0.10 & 0.05 & -2.33 & .02 & -0.19 & -0.02 \\
\hline
\end{tabular}

Note. Results of the PROCESS regression analysis examining the parental sensitivity $\times$ age interaction effect on left amygdala-mPFC connectivity. The top row of the table describes the model characteristics, while the lower rows describe characteristics of the dependent variables. LLCI = lower limit confidence interval; ULCI = upper limit confidence interval 
Table 4

Post-hoc analyses of sensitivity $\times$ age interaction effects

\begin{tabular}{|c|c|c|c|c|c|}
\hline \multirow[t]{3}{*}{ Sensitivity measure } & \multirow[t]{3}{*}{ Laterality } & \multicolumn{4}{|l|}{ Sensitivity } \\
\hline & & \multicolumn{2}{|l|}{$-1 \mathrm{SD}$} & \multicolumn{2}{|l|}{$+1 \mathrm{SD}$} \\
\hline & & $\mathrm{B}(95 \% \mathrm{CI})$ & $p$ & $\mathrm{~B}(95 \% \mathrm{CI})$ & $p$ \\
\hline \multirow[t]{2}{*}{ Parental sensitivity } & Right amygdala & $0.11(0.03 ; 0,18)$ & .004 & $-0.07(-0.16 ; 0.02)$ & .12 \\
\hline & Left amygdala & $0.06(-0.00 ; 0.13)$ & .06 & $-0.06(-0.14 ; 0.02)$ & .12 \\
\hline \multirow[t]{2}{*}{ Maternal sensitivity } & Right amygdala & $0.09(0.02 ; 0.17)$ & .01 & $-0.03(-0.11 ; 0.06)$ & .52 \\
\hline & Left amygdala & \multicolumn{4}{|c|}{ no significant clusters } \\
\hline \multirow[t]{2}{*}{ Paternal sensitivity } & Right amygdala & \multicolumn{4}{|c|}{ no significant clusters } \\
\hline & Left amygdala & \multicolumn{4}{|c|}{ no significant clusters } \\
\hline
\end{tabular}

Note. Table describes the regression coefficients of age on amygdala-mPFC connectivity at -/+ 1 standard deviation (SD) of sensitivity 
Table 5

Full model of maternal sensitivity $\times$ age interaction effect on right amygdala-mPFC connectivity

\begin{tabular}{lllllll}
\hline \multicolumn{1}{c}{$r$} & $r^{2}$ & $M S E$ & $F$ & $d f 1$ & $d f 2$ & $p$ \\
& .10 & 0.07 & 1.97 & 6 & 105 & .08 \\
\hline Constant & $b$ & $S E$ & $t$ & $p$ & $L L C I$ & $U L C I$ \\
Gender & 0.43 & 0.25 & 1.69 & .09 & -0.07 & 0.93 \\
IQ & 0.10 & 0.05 & 1.83 & .07 & -0.01 & 0.20 \\
Maternal education & -0.00 & 0.00 & -0.44 & .66 & -0.00 & .00 \\
Maternal sensitivity & -0.02 & 0.06 & 0.28 & .78 & -.11 & .14 \\
Age rs-fMRI & -0.02 & 0.04 & -0.31 & .76 & -0.09 & .06 \\
Maternal sensitivity $\times$ age & -0.08 & 0.04 & -2.13 & .04 & -0.16 & -0.01 \\
\hline
\end{tabular}

Note. Results of the PROCESS regression analysis examining the maternal sensitivity $\times$ age interaction effect on right amygdala-mPFC connectivity. The top row of the table describes the model characteristics, while the lower rows describe characteristics of the dependent variables. LLCI = lower limit confidence interval; ULCI = upper limit confidence interval 
Table 6

Sensitivity $\times$ age $\times$ gender effects on amygdala-mPFC functional connectivity

\section{MNI coordinates}

Cluster Region $\quad$ Size $\quad$\begin{tabular}{lllllll}
\cline { 4 - 7 } & $\mathrm{x}$ & $\mathrm{y}$ & $\mathrm{z}$ & $z$ & $p$
\end{tabular}

Parental sensitivity - Right amygdala

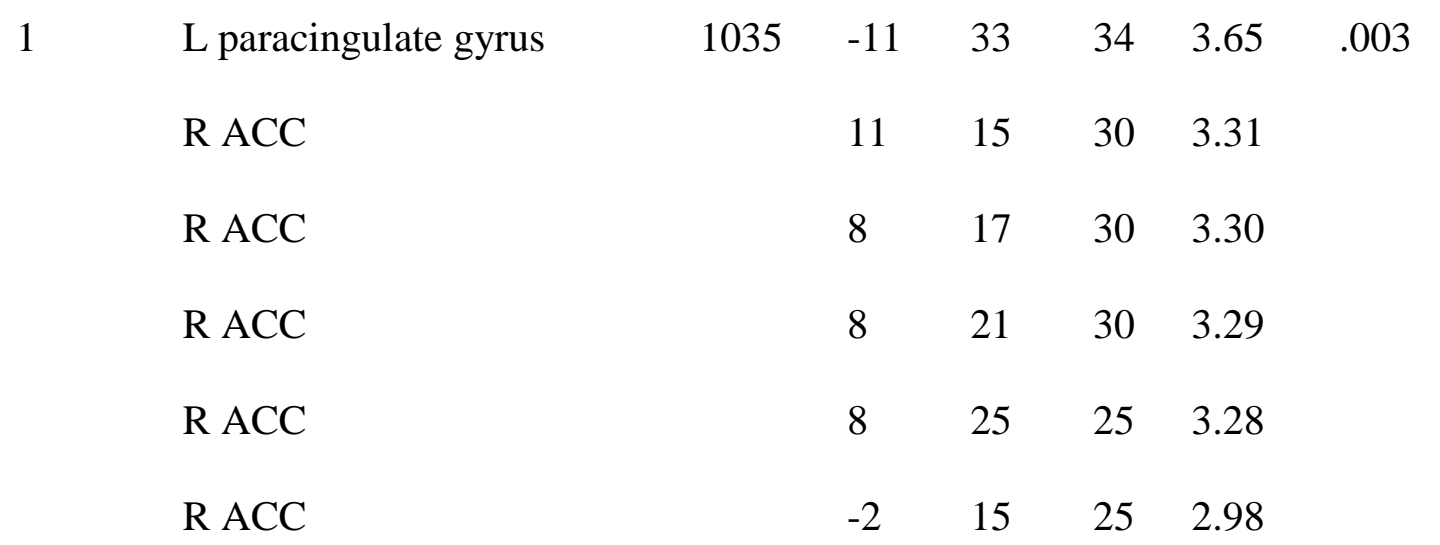

Parental sensitivity - Left amygdala

$\begin{array}{lllllll}1 & 1597 & -11 & 29 & 34 & 3.64 & <.001 \\ \text { L paracingulate gyrus } & -11 & 33 & 34 & 3.61 & \\ \text { R ACC } & 7 & 21 & 30 & 3.59 \\ \text { L SFG } & -11 & 38 & 34 & 3.58 \\ \text { L frontal pole } & -9 & 66 & 14 & 3.33 \\ \text { L paracingulate gyrus } & -11 & 18 & 45 & 3.32\end{array}$

Maternal sensitivity - Right amygdala

$\begin{array}{lllllll}1 & 432 & 7 & 17 & 30 & 4.29 & .04 \\ \text { L ACC } & -2 & 15 & 25 & 3.35 & \\ \text { ACC } & & 0 & 21 & 28 & 3.30 & \end{array}$




\begin{tabular}{lllllll}
\hline L SFG & -11 & 40 & 34 & 3.04 & \\
& & & & & \\
L paracingulate gyrus & -11 & 20 & 45 & 2.67 & \\
Parental sensitivity - Right amygdala & & & & & & \\
1 & 737 & 14 & 32 & 7 & 3.10 & .01 \\
R WM & 9 & 28 & 16 & 3.08 & \\
R ACC & 14 & 30 & 16 & 2.87 & \\
R WM/ACC & 9 & 10 & 30 & 2.87 \\
R WM/ACC & -4 & 36 & 16 & 2.81 & \\
L ACC & -11 & 36 & 8 & 2.80 &
\end{tabular}

Parental sensitivity - Left amygdala

$\begin{array}{lllllll}1 & 2448 & -9 & 68 & 14 & 3.65 & <.001 \\ \text { L frontal pole SFG } & -7 & 37 & 43 & 3.62 & \\ \text { R frontal pole } & 11 & 70 & 14 & 3.49 & \\ \text { L paracingulate gyrus } & -11 & 18 & 45 & 3.39 & \\ \text { R ACC } & 9 & 30 & 16 & 3.30 \\ \text { L SFG } & -7 & 33 & 50 & 3.24\end{array}$

\footnotetext{
Note. Results of the general linear model of the sensitivity $\times$ age $\times$ gender interaction effects on amygdala-mPFC functional connectivity. $\mathrm{WM}=$ white matter, $\mathrm{ACC}=$ anterior cingulate cortex, $\mathrm{SFG}=$ superior frontal gyrus
} 
Table 7

Post-hoc analyses of sensitivity $\times$ age $\times$ gender interaction effects

\begin{tabular}{|c|c|c|c|c|c|c|}
\hline \multirow[t]{3}{*}{ Sensitivity measure } & \multirow[t]{3}{*}{ Laterality } & \multirow[t]{3}{*}{ Gender } & \multicolumn{4}{|l|}{ Sensitivity } \\
\hline & & & \multicolumn{2}{|l|}{$-1 \mathrm{SD}$} & \multicolumn{2}{|l|}{$+1 \mathrm{SD}$} \\
\hline & & & B (95\% CI) & $p$ & B (95\% CI) & $p$ \\
\hline \multirow[t]{4}{*}{ Parental sensitivity } & Right amygdala & Boys & $-0.05(-0.14 ; 0.05)$ & .34 & $-0.01(-0.13 ; 0.12)$ & .93 \\
\hline & & Girls & $0.26(0.15 ; 0.36)$ & $<.001$ & $-.12(-0.23 ;-0.01)$ & .03 \\
\hline & Left amygdala & Boys & $-0.04(-0.14 ; 0.05)$ & .36 & $0.07(-0.06 ; 0.20)$ & .26 \\
\hline & & Girls & $0.20(0.10 ; 0.31)$ & $<.001$ & $-0.10(-0.21 ; 0.01)$ & .08 \\
\hline \multirow[t]{3}{*}{ Maternal sensitivity } & Right amygdala & Boys & $-0.04(-0.13 ; 0.04)$ & .35 & $-0.02(0.15 ; 0.11)$ & .80 \\
\hline & & Girls & $0.29(0.14 ; 0.42)$ & $<.001$ & $-0.08(-0.20 ; 0.04)$ & .17 \\
\hline & Left amygdala & & \multicolumn{2}{|c|}{ no significant clusters } & & \\
\hline \multirow[t]{4}{*}{ Paternal sensitivity } & Right amygdala & Boys & $-0.04(-0.15 ; 0.07)$ & .45 & $-0.00(-0.12 ; 0.12)$ & .99 \\
\hline & & Girls & $0.23(0.12 ; 0.35)$ & $<.001$ & $-0.11(-0.25 ; 0.02)$ & .10 \\
\hline & Left amygdala & Boys & $-0.05(-0.15 ; 0.05)$ & .36 & $0.10(-0.01 ; 0.22)$ & .07 \\
\hline & & Girls & $0.18(0.07 ; 0.30)$ & .001 & $-0.07(-0.20 ; 0.06)$ & .28 \\
\hline
\end{tabular}

Note. Table describes the regression coefficients of age on amygdala-mPFC connectivity at $-/+1$ standard deviation (SD) of sensitivity for boys and girls separately 


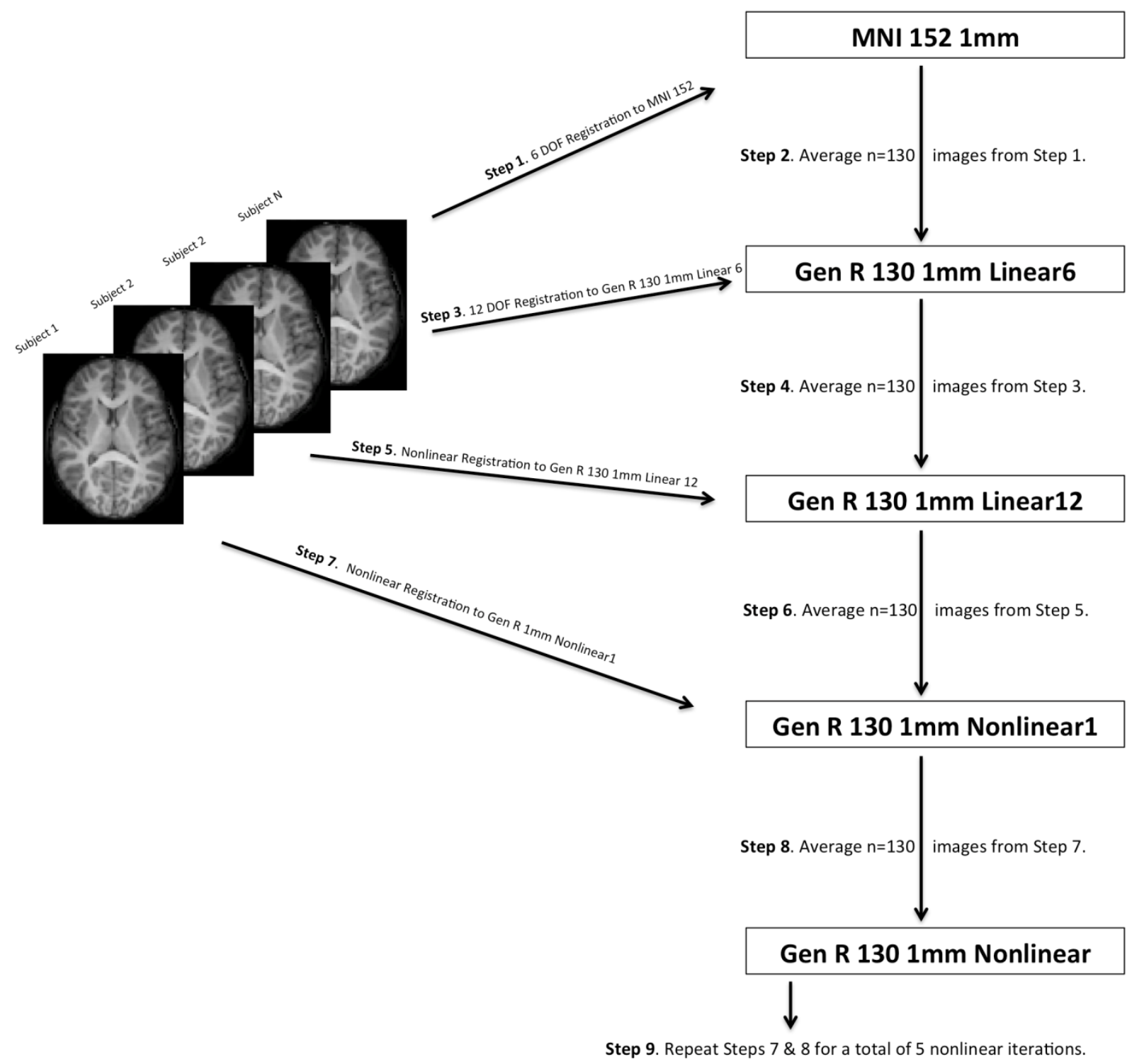

Figure 1. Study-specific, age-appropriate template for registration 


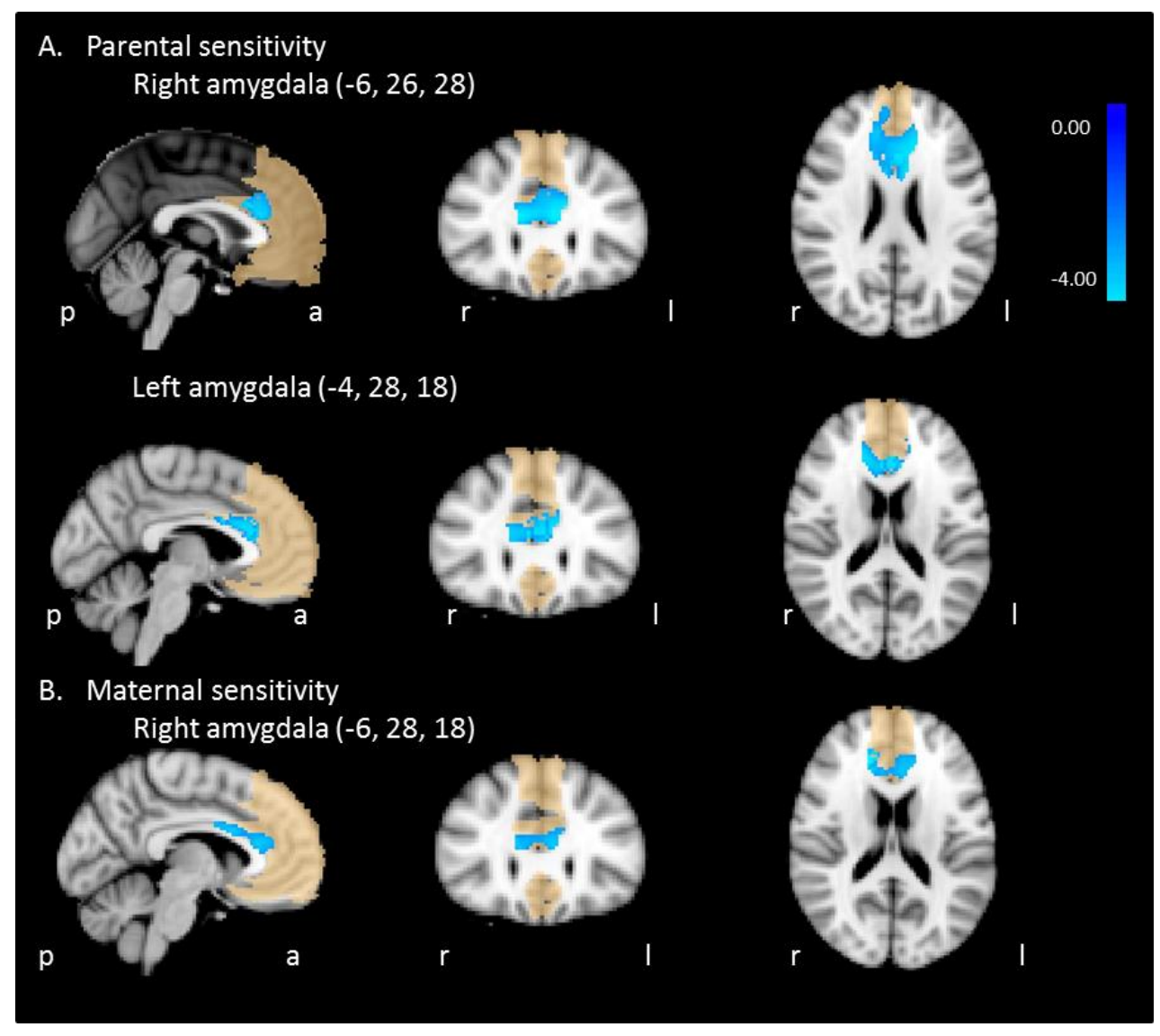

Figure 2. Sensitivity $\times$ age interaction effect on amygdala-mPFC functional connectivity. A. Parental sensitivity B. Maternal sensitivity. MPFC mask shown in background. 


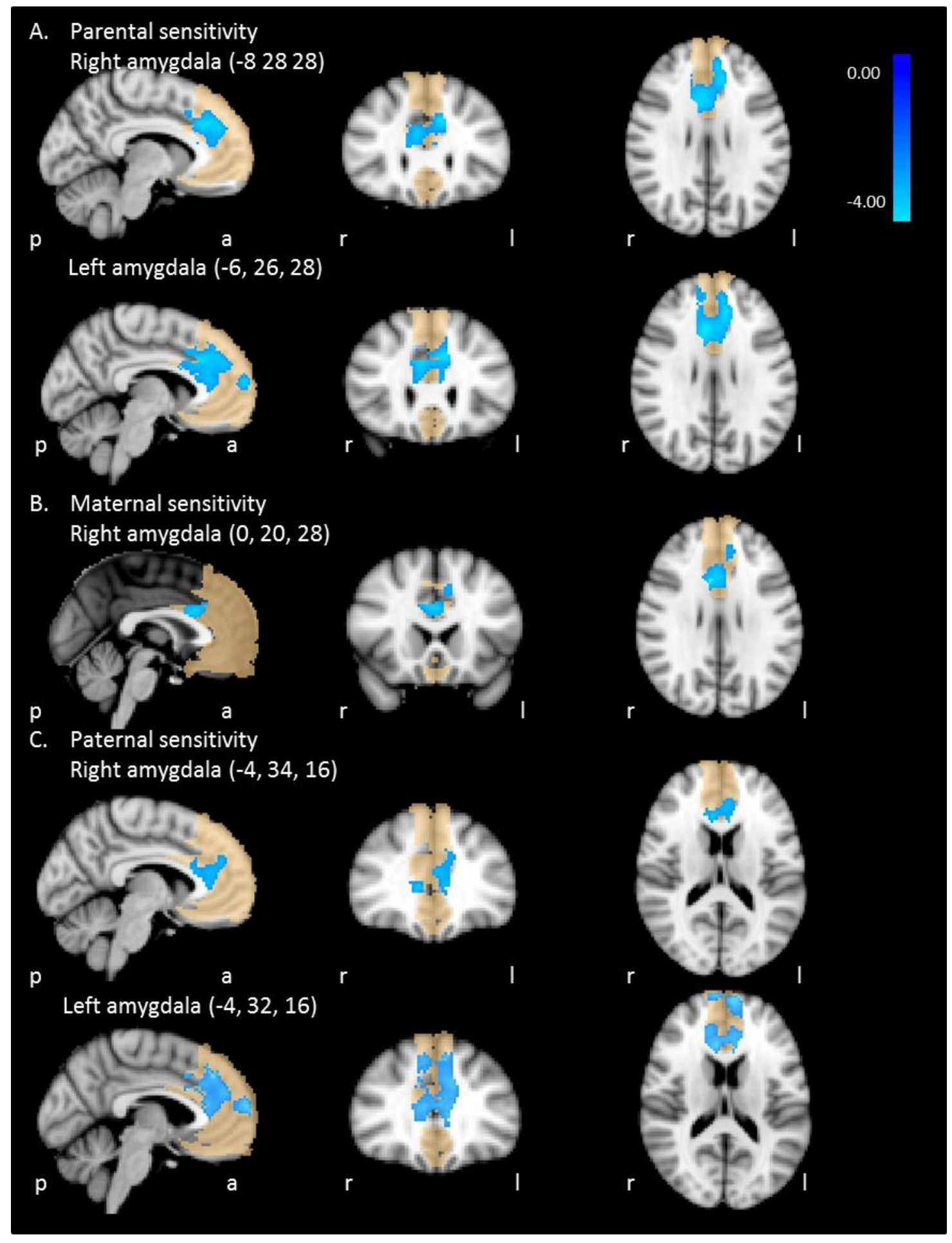

Figure 3. Sensitivity $\times$ age $\times$ gender interaction effect on amygdala-mPFC functional connectivity. A. Parental sensitivity, B. Maternal sensitivity, C. Paternal sensitivity 